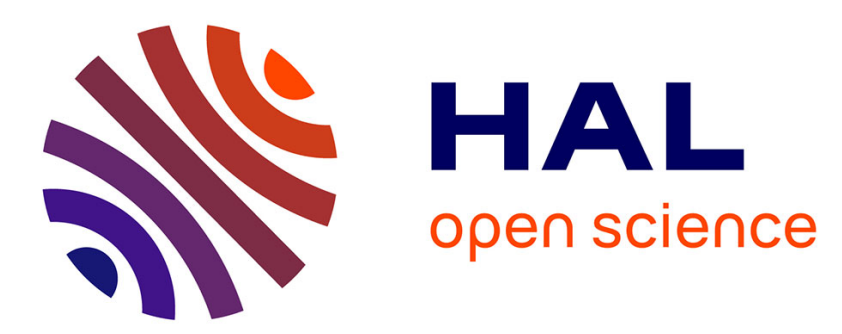

\title{
Diaphragm dysfunction during weaning from mechanical ventilation: an underestimated phenomenon with clinical implications
}

\author{
Martin Dres, Alexandre Demoule
}

\section{- To cite this version:}

Martin Dres, Alexandre Demoule. Diaphragm dysfunction during weaning from mechanical ventilation: an underestimated phenomenon with clinical implications. Critical Care, 2018, 22, pp.73. 10.1186/s13054-018-1992-2 . hal-01761437

\section{HAL Id: hal-01761437 \\ https://hal.sorbonne-universite.fr/hal-01761437}

Submitted on 9 Apr 2018

HAL is a multi-disciplinary open access archive for the deposit and dissemination of scientific research documents, whether they are published or not. The documents may come from teaching and research institutions in France or abroad, or from public or private research centers.
L'archive ouverte pluridisciplinaire HAL, est destinée au dépôt et à la diffusion de documents scientifiques de niveau recherche, publiés ou non, émanant des établissements d'enseignement et de recherche français ou étrangers, des laboratoires publics ou privés.

\section{(c)(1)}

Distributed under a Creative Commons Attribution| 4.0 International License 


\title{
Diaphragm dysfunction during weaning from mechanical ventilation: an underestimated phenomenon with clinical implications
}

\author{
Martin Dres ${ }^{1,2^{*}}$ and Alexandre Demoule ${ }^{1,2}$
}

\begin{abstract}
This article is one of ten reviews selected from the Annual Update in Intensive Care and Emergency Medicine 2018. Other selected articles can be found online at https://www.biomedcentral.com/collections/ annualupdate2018. Further information about the Annual Update in Intensive Care and Emergency Medicine is available from http://www.springer.com/series/8901.
\end{abstract}

\section{Background}

Weaning failure is defined as the inability to liberate a patient from the ventilator. Therefore, the term 'weaning failure' encompasses the failure of a spontaneous breathing trial (SBT) or the need to resume mechanical ventilation after extubation within $48 \mathrm{~h}$ to seven days [1]. The majority of patients are safely weaned from the ventilator after a first attempt, some are even extubated without any SBT [2]. Thereby, weaning failure occurs in a minority of patients but represents an important burden in term of days of mechanical ventilation, intensive care unit (ICU) lengths of stay and morbi-mortality [2]. Investigating the causes of weaning failure is therefore crucial because the duration of mechanical ventilation for those who fail the SBT [2] and the reintubation for those in whom reintubation is needed $[3,4]$ have both been associated with poor outcomes. Ultimately, identifying the reason why a patient fails the weaning process might help to reduce the duration of mechanical ventilation and hence to improve patient outcomes.

\footnotetext{
* Correspondence: martin.dres@aphp.fr

${ }^{1}$ Sorbonne Universités, UPMC Univ Paris 06, INSERM, UMRS1158 Neurophysiologie respiratoire expérimentale et clinique, Paris, France ${ }^{2} \mathrm{AP}$-HP, Groupe Hospitalier Pitié-Salpêtrière Charles Foix, Service de Pneumologie et Réanimation Médicale (Département "R3S"), Paris, France
}

Recent findings suggest that diaphragm dysfunction is frequently involved during weaning failure $[5,6]$ and that it is associated with poor prognosis at time of liberation from mechanical ventilation $[7,8]$. Until recently, exploration of the diaphragm has not been convenient to achieve at the bedside. This factor may explain the growing interest in ultrasound. Diaphragm ultrasound provides non-invasive indices that describe the structure and the function of the muscle. Herein, we summarize the mechanisms of diaphragm dysfunction in the critically ill and describe current approaches aimed at assessing diaphragm function at the bedside. We discuss some recent aspects of the epidemiology and risk factors for diaphragm dysfunction at the time of weaning from mechanical ventilation. Finally, latest advances regarding preventive and curative strategies for diaphragm dysfunction are presented.

\section{Mechanisms of diaphragm function}

A comprehensive review describing the mechanisms of diaphragm dysfunction in the ICU has been published recently [9]. In the following lines, we briefly summarize the existing literature on this topic. The main experimental model of diaphragm dysfunction comes from experimental studies where ventilator-induced diaphragm inactivity was used as the promoter. From these studies, ventilatorinduced diaphragm dysfunction was defined in 2004 as loss of diaphragmatic force-generating capacity specifically related to the use of mechanical ventilation [10]. Elucidating the mechanisms leading to diaphragm dysfunction requires biopsies, an option rarely used in the ICU. Nevertheless, in recent years, better understanding has been achieved by obtaining diaphragm specimens from very specific populations, such as brain dead organ donors [11] and thoracic surgery patients [12]. It is now established that diaphragm dysfunction is accompanied by two landmark pathophysiological features: disuse atrophy and microstructural changes 
[9]. The first study reporting evidence of diaphragm atrophy in adults was published by Levine and coworkers [11]. This group established, in 14 brain dead organ donors, that disuse atrophy occurred shortly after the start of controlled mechanical ventilation [11]. In addition, muscle fiber atrophy was associated with signs of increased oxidative stress and with an increase in muscle proteolysis biomarkers. Oxidative stress, downregulation of protein synthesis and activation of proteolytic pathways represent the biochemical changes of diaphragm dysfunction.
Interestingly, no such atrophy or sign of oxidative stress has been noted in the pectoralis [11] or latissimus dorsi [12] muscles.

\section{Detection of diaphragm dysfunction in ICU patients}

Several methods are now available to detect the presence of diaphragm dysfunction in critically ill patients (Fig. 1). Although bilateral anterior magnetic phrenic stimulation (BAMPS) is considered as the reference method [13], it

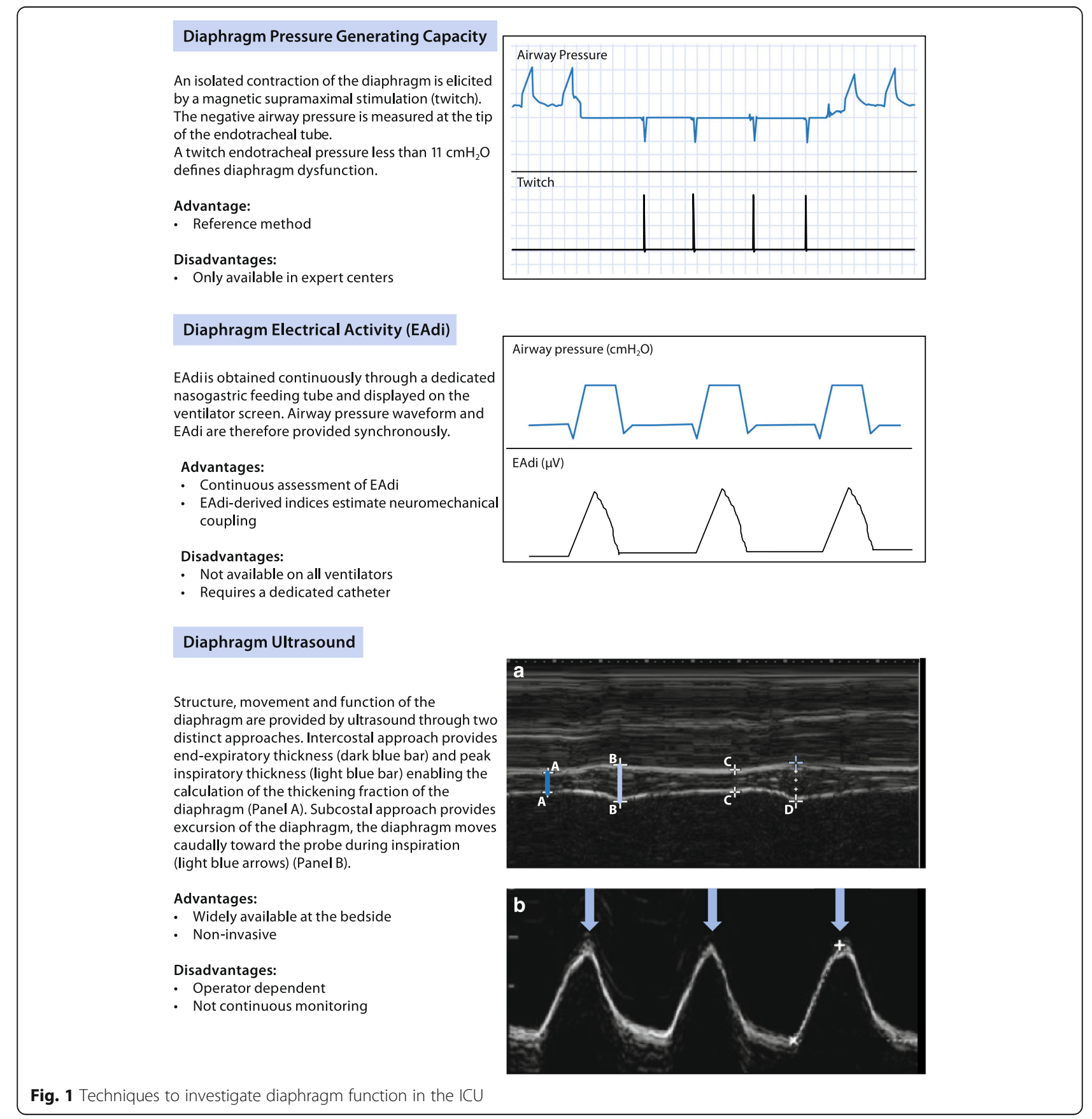


must be pointed out that it is a relatively recent technique, used in the ICU only in the last 20 years $[14,15]$. Physiologically speaking, diaphragm dysfunction can be defined as a reduced ability of the diaphragm to generate a negative intrathoracic pressure, regardless of the origin of the observation. BAMPS elicits an isolated contraction of the diaphragm and enables the change (twitch) in endotracheal pressure (Pet,tw) or in transdiaphragmatic pressure (Pdi,tw) to be measured [15]. Based on this method, diaphragm dysfunction is defined as a decrease in its capacity to generate a negative intrathoracic pressure, usually less than $11 \mathrm{cmH}_{2} \mathrm{O}$ [13]. Although this method provides a rigorous assessment of diaphragm function, it is only available in expert centers and requires costly equipment, precluding its generalization.

By contrast, ultrasound is widely available in every ICU and, furthermore, it is totally non-invasive. The use of ultrasound is growing in the ICU and may become a key player in the evaluation of diaphragm function during weaning. From two distinct approaches, diaphragm ultrasound provides structural and functional assessment of the muscle, the right side being the most frequently evaluated. Using the intercostal approach, the diaphragm is examined on its zone of apposition to the rib cage. At this location, ultrasound enables measurement of the end-expiratory (Tee) and peak inspiratory (Tei) diaphragm thickness. The diaphragm thickening fraction (TFdi) is computed as the difference between Tei and Tee, divided by Tee. TFdi is tightly correlated with transdiaphragmatic pressure [16], an estimator of diaphragm function [13]. Only one study has compared diaphragm ultrasound and BAMPS and reported a good correlation between TFdi and the change in tracheal pressure generated by the phrenic nerves stimulation $(r=0.87)$, provided that patients trigger the ventilator [7]. According to this study, a TFdi cut-off of $29 \%$ is an optimal value to identify diaphragm dysfunction [7]. With the subcostal approach, the diaphragm is assessed by the excursion of the dome. Using transdiaphragmatic pressure as a reference, Lerolle et al. identified a diaphragm excursion cut-off less than $2.5 \mathrm{~cm}$ to define diaphragm dysfunction [17].

Electromyography (EMG) of the diaphragm was first described more than 50 years ago. It provides diaphragm electrical activity (EAdi), which is the spatial and temporal summation of neural impulses. Diaphragm EMG can be obtained easily and continuously through the use of a dedicated nasogastric feeding catheter equipped with multiarray electrodes. EAdi is tightly correlated to a patient's inspiratory effort and is a good estimate of diaphragm function. Combining EAdi with the breathing pattern provide indices that evaluate the diaphragm's contribution to the generation of tidal volume $\left(\mathrm{V}_{\mathrm{T}}\right)$. For example, the ratio of $V_{T}$ to $E A d i\left(V_{T} / E A d i\right)$ represents the neuroventilatory efficiency of the diaphragm. When $\mathrm{V}_{\mathrm{T}}$ /EAdi is high, it indicates that a patient generates a large $\mathrm{V}_{\mathrm{T}}$ with a relatively low EAdi, whereas when $\mathrm{V}_{\mathrm{T}}$ /EAdi is low, this indicates that despite a high EAdi, $\mathrm{V}_{\mathrm{T}}$ is low. This index reflects the ability of the diaphragm to convert respiratory drive into ventilation. A low $\mathrm{V}_{\mathrm{T}}$ /EAdi suggests severe impairment of neuromechanical coupling. EAdi-derived indices have been used to discriminate patients with weaning failure $[18,19]$. Interestingly, monitoring neuroventilatory efficiency during an SBT enables very early (after $3 \mathrm{~min}$ ) detection of patients likely to fail the test [18]. However, the performance of EAdi-derived indices to predict weaning failure is not better than the performance of the rapid shallow breathing index [18], a popular weaning predictor that is not specific to the diaphragm.

\section{Risk factors and population concerned by diaphragm dysfunction at time of weaning}

Several risk factors are associated with the occurrence of diaphragm dysfunction in the ICU. In the sickest patients, it is likely that multiple factors hit simultaneously. Some are present before the ICU admission (sepsis, shock) while others develop during the stay (mechanical ventilation) (Fig. 2). Confirming a previous report showing that sepsis induced preferential diaphragm atrophy [20], Demoule et al. established that, on admission, sepsis is an independent risk factor for diaphragm dysfunction [21]. An important but not elucidated question is whether the delay between sepsis onset and ICU admission is correlated with the severity of the dysfunction. In the same study [21], disease severity, as assessed with Simplified Acute Physiology Score (SAPS) II, was also independently associated with diaphragm dysfunction, suggesting that diaphragm dysfunction behaves as any other organ failure. Shock states, in particular of cardiogenic origin, are associated with diaphragm dysfunction [22]. The imbalance between oxygen supply and demand during cardiogenic shock can ultimately result in diaphragm fatigue

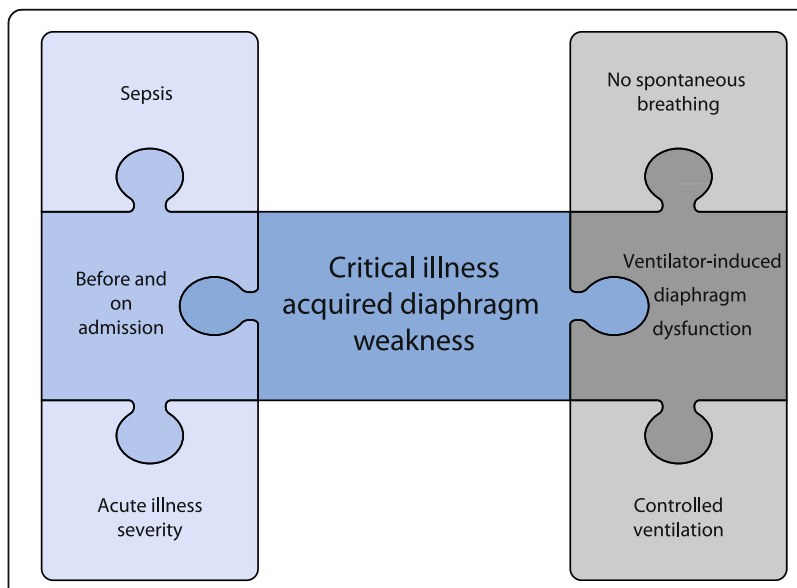

Fig. 2 Main factors contributing to diaphragm weakness before and on ICU admission and after exposure to mechanical ventilation 
[22]. Although these findings performed in animals have not been replicated in humans, they are based on a strong methodology and have a strong 'face validity' for clinicians.

After ICU admission, patients may be exposed to prolonged mechanical ventilation, a risk factor for diaphragm dysfunction [10]. Two studies used BAMPS to serially investigate diaphragm function in a limited number of patients $[23,24]$. Both reported a time-dependent deterioration in diaphragm function with increased duration of mechanical ventilation $[23,24]$. Speculating that atrophy would constitute a meaningful marker of diaphragm function, these findings were confirmed by Grosu et al. who observed a time-dependent decline in diaphragm thickness by ultrasound in seven patients receiving mechanically ventilation [25]. Larger cohorts [26, 27] have now confirmed this very preliminary observation [25]. As expected, in a series of medical ICU patients undergoing mechanical ventilation in whom diaphragm function was investigated by the phrenic nerve stimulation technique at the time of weaning, the duration of mechanical ventilation from intubation to weaning was associated with the occurrence of diaphragm dysfunction [6]. Nevertheless, this effect was not retained in a multivariable analysis incorporating other risk factors [6]. These findings support the hypothesis that rather than mechanical ventilation per se, it is the inactivity of the diaphragm that is the critical determinant of dysfunction. This assumption was incidentally confirmed by Goligher et al. who reported that changes in diaphragm thickness were modulated by a patient's inspiratory efforts: the lower the inspiratory effort, the greater the atrophy [26]. In a subsequent study, the same team also demonstrated that diaphragm atrophy developing during the ICU stay was associated with prolonged duration of mechanical ventilation, increased risk of reintubation and tracheostomy [28]. In addition to mechanical ventilation, some drugs, such as corticosteroids and neuromuscular blocking agents, may generate diaphragm dysfunction but their effects are not univocal.

Critical illness polyneuropathy and myopathy are frequently observed in patients with weaning failure [29] and coexist with respiratory muscle weakness $[5,30]$. Since the detection of diaphragm dysfunction is a challenge in daily practice, it would be tempting to use critical illness polyneuropathy and myopathy as a surrogate. However, accumulating evidence indicates that it would be a cursory glance. First, as demonstrated by experimental and clinical studies [11,31], the consequences of prolonged unloading of the diaphragm are distinct from the consequences of unloading limb muscles. Second, the diaphragm seems preferentially affected compared to limb muscles in septic patients [20] and to the latissimus dorsi muscle in mechanically ventilated patients [12]. Whether diaphragm dysfunction is a respiratory component of critical illness polyneuropathy and myopathy is therefore not established. Hence, diaphragm dysfunction is not always present in patients with critical illness polyneuropathy and myopathy [5] and the correlation between the two diseases is weak [6] or lacking [5]. In addition, there is a distinct difference between diaphragm dysfunction and critical illness polyneuropathy and myopathy, as the latter condition is often associated with conduction abnormalities in electrophysiological studies [9]. The prognosis of both diseases is also clearly different as diaphragm dysfunction is more likely to be associated with weaning failure and ICU mortality, whereas critical illness polyneuropathy and myopathy is associated with prolonged duration of ICU stay but not with mortality [6]. Therefore, the presence of critical illness polyneuropathy and myopathy is not sufficient to establish the presence of diaphragm dysfunction and further investigations are needed before confirming the diagnosis.

\section{Presence and impact of diaphragm dysfunction at the time of weaning}

Weaning failure is provoked by a constellation of causes, some of them potentially linked. When the capacity of the system (respiratory muscle strength, respiratory drive) is reduced, the load (lung disease, fluid overload, cardiac dysfunction, abnormality of the chest wall) is increased, leading to respiratory load/capacity imbalance. The weight of the diaphragm in the load/capacity balance is heavy but it is important to remember that decreased capacity of the respiratory system can also be the consequence of impaired respiratory drive or neuromuscular dysfunction. Impaired respiratory drive is an obvious cause of weaning failure. It can be easily identified by a simple physical examination showing signs of encephalitis or stroke. Since weaning from the ventilator in this category of patients is a specific issue, it is not addressed in the present review.

As noted earlier, exploring diaphragm function is not straightforward in the critically ill, which may explain why some investigators opted rather to investigate global respiratory function [30]. Thus, respiratory muscle weakness has been reported to be associated with delayed weaning in some studies [30], but not in all [5]. This discrepancy may be explained by differences in duration of mechanical ventilation and by population characteristics in the two studies $[5,30]$. Looking at diaphragm function, there is now compelling evidence to establish a relationship between diaphragm dysfunction and weaning failure $[6,8,17]$. However, the incidence of diaphragm dysfunction is not yet completely established and may depend on the population that is investigated and on the diagnostic method that is employed. Accordingly, the incidence of diaphragm dysfunction ranges from 23 to $80 \%$ (Table 1). Using diaphragm ultrasound, Kim et al. identified diaphragm dysfunction in 24/82 medical ICU patients (29\%) 
Table 1 Prevalence of diaphragm dysfunction at weaning from mechanical ventilation

\begin{tabular}{lll}
\hline Author [ref] & Populations & Prevalence \\
\hline Studies using ultrasound & & \\
Kim et al. [8] & Medical ICU & 24/82 (29\%) \\
Jiang et al. [47] & Medical ICU & $20 / 55(36 \%)$ \\
DiNino et al. [34] & Medical ICU & $15 / 66(23 \%)$ \\
Lu et al. [48] & Prolonged MV & $14 / 41$ (34\%) \\
Studies using pressure generating capacity & \\
Watson et al. [15] & Medical ICU & $26 / 33(79 \%)$ \\
Supinski et al. [49] & Medical ICU & $48 / 57(84 \%)$ \\
Jung et al. [5] & Medical-surgical ICU-AW & $32 / 40(80 \%)$ \\
Laghi et al. [50] & Prolonged MV - COPD & $12 / 16(75 \%)$ \\
Dres et al. [6] & Medical ICU & $48 / 76(63 \%)$ \\
Lerolle et al. [17] & Post-cardiac surgery & $19 / 28(68 \%)$ \\
\hline
\end{tabular}

ICU: intensive care unit; $M V$ : mechanical ventilation; ICU-AW: ICU-acquired

weakness; COPD: chronic obstructive pulmonary disease

undergoing a first SBT [8]. Diaphragm dysfunction was associated with a longer total duration of mechanical ventilation (576 vs. $203 \mathrm{~h}, p<0.01$ ) and a longer weaning duration (401 vs. $90 \mathrm{~h}, \mathrm{p}<0.01$ ) [8]. Using BAMPs at the time of weaning, diaphragm dysfunction was present in $48 / 76$ (63\%) non-selected ICU patients [6] and in 32/40 (80\%) patients with critical illness polyneuropathy and myopathy [5]. In the first study, diaphragm dysfunction was associated with difficult weaning, prolonged duration of mechanical ventilation, prolonged ICU stay and greater ICU and hospital mortality [6]. In the second study [5], among the 13 patients who died during the ICU stay, 10 (77\%) had diaphragm dysfunction on the day of the SBT.

Because of its negative impact on weaning, it may be worthwhile to use diaphragm function as a predictor of weaning failure. Patients with weaning failure consistently have a lower TFdi compared to patients with successful weaning ([5, 6, 32-35]; Table 2). From these studies, the optimal Tfdi cut-off to predict successful weaning ranges from 20 to $36 \%$ depending on the ventilator support provided during the measurement; the higher the support, the lower the Tfdi.

\section{Management of weaning failure as a result of diaphragm dysfunction}

As soon as diaphragm dysfunction is diagnosed in a patient failing the weaning process, there is a need for caregivers to develop strategies aimed at reducing the duration of mechanical ventilation. However, efforts have to be taken before this step by applying preventive strategies.

\section{Preventive strategies}

Maintaining spontaneous breathing under mechanical ventilation alleviates diaphragm dysfunction in animals
Table 2 Diaphragm ultrasound findings in patients with successful and failed weaning

\begin{tabular}{|c|c|c|c|c|}
\hline & $\begin{array}{l}\text { Weaning } \\
\text { test }\end{array}$ & $\begin{array}{l}\text { Successful } \\
\text { weaning }\end{array}$ & $\begin{array}{l}\text { Failed } \\
\text { weaning }\end{array}$ & $\begin{array}{l}\text { Cut-off to predict } \\
\text { successful weaning }\end{array}$ \\
\hline \multicolumn{5}{|c|}{ Diaphragm thickening fraction } \\
\hline \multirow[t]{2}{*}{ DiNino et al. [34] } & PSV 8-0 & - & - & $>36 \%$ \\
\hline & T-tube & - & - & $>27 \%$ \\
\hline Ferrari et al. [33] & T-tube & - & - & $>36 \%$ \\
\hline Blumhof et al. [32] & PSV 5-5 & $38 \%$ & $18 \%$ & $>20 \%$ \\
\hline Farghaly et al. [35] & PSV 8-0 & $60 \%$ & $31 \%$ & $>34 \%$ \\
\hline Dres et al. [6] & PSV 7-0 & $35 \%$ & $19 \%$ & $>29 \%$ \\
\hline \multirow[t]{2}{*}{ Jung et al. [5] } & PSV 7-0 & $20 \%$ & $9 \%$ & - \\
\hline & T-tube & $20 \%$ & $12 \%$ & - \\
\hline \multicolumn{5}{|c|}{ Diaphragm excursion } \\
\hline Dres et al. [6] & PSV 7-0 & $1.10 \mathrm{~cm}$ & $0.80 \mathrm{~cm}$ & $0.95 \mathrm{~cm}$ \\
\hline Kim et al. [8] & - & - & - & $1.00 \mathrm{~cm}$ \\
\hline Carrie et al. [51] & PSV 7-0 & 4.10 & 3.0 & $2.70 \mathrm{~cm}$ \\
\hline Jiang et al. [47] & T-tube & 1.45 & 0.84 & $1.10 \mathrm{~cm}$ \\
\hline
\end{tabular}

PSV: pressure support ventilation

[36, 37]. Accordingly, a first preventive task may be to favor spontaneous inspiratory effort in patients exposed to mechanical ventilation. This could be achieved by optimizing the level of ventilator assistance and by enhancing sedation strategy. The balance between diaphragm unloading and diaphragm loading is, however, difficult to determine. Although no data are available at this time, the use of ultrasound may be useful to monitor diaphragm activity and to tailor ventilator support in this context. Another interesting option, although not yet investigated in humans, is to cause intermittent contraction of the diaphragm in order to prevent atrophy [38]. Diaphragm pacing can be applied through a transvenous phrenic nerve pacing system designed to be percutaneously placed in the left subclavian vein. This technique has been employed in pigs exposed to mechanical ventilation. Mechanically ventilated (but not paced) pigs suffered significant diaphragm atrophy and loss of endurance. In contrast, pigs that received transvenous phrenic nerve pacing in synchrony with ventilation exhibited less diaphragm atrophy [38]. Whether preventive diaphragm pacing would be possible and effective in patients receiving mechanically ventilation has yet to be proved. Targeting the population who could benefit from this strategy will be the next challenge.

\section{Curative strategies}

There is no specific treatment for diaphragm dysfunction. Management of patients failing the weaning process in whom diaphragm dysfunction has been identified require global evaluation and a multi-approach strategy. We will first review the possible tasks that could be applied in daily 
practice and then briefly discuss some promising research developments.

All potential causes of weaning failure need to be looked for and removed before resuming the weaning process. Notably, attention has to be paid to the occurrence of weaning-induced cardiac dysfunction, a frequent and treatable cause of weaning failure [39]. Several methods exist to detect weaning-induced cardiac dysfunction $[39,40]$ and the use of nitrates or diuretics is a good option in this context. Whether diaphragm dysfunction may worsen or alleviate underlying cardiac dysfunction is unclear and the coexistence of these two frequent causes of weaning failure has to be investigated further. Although pleural effusion is not particularly associated with weaning failure [41], some data suggest that removing large pleural effusions may improve diaphragm function [42]. However, the impact of such an intervention on weaning has not yet been established.

If diaphragm dysfunction is identified as a reason for weaning failure, improving respiratory muscle function is a meaningful option. In the ICU, muscle-directed therapies have used various forms of volitional or electrically-induced exercises. The most promising therapy seems to be inspiratory muscle training but only a few studies have been conducted. When looking at studies on inspiratory muscle training, two factors must be considered. First, the modalities of the 'control' arm to which inspiratory muscle training is compared should be carefully examined because there is considerable heterogeneity in practice. Second, the impact of the intervention should have clinical relevance. There is no real benefit of improving inspiratory muscle force itself, attention has to be paid to clinical outcomes, such as shortened duration of mechanical ventilation, successful extubation or greater survival. The largest study enrolled 69 long-term ventilated patients and randomized them to receive either inspiratory muscle training or control training [43]. Inspiratory muscle training consisted of a 5-day-a-week program with four sets of 6 to 10 breaths per day. During each set, patients breathed through a threshold inspiratory muscle trainer and patients in the control group used a resistive inspiratory muscle training device set at the largest opening. In this study, inspiratory muscle training significantly improved maximal inspiratory pressure and successful weaning was more likely [43]. In another study, it was recently reported that inspiratory muscle training performed after successful extubation improved respiratory muscle function but without any clinical benefit [44]. Furthermore, the intervention group had a trend toward greater mortality ( 12 vs. $0 \%, p=0.051$ ). In summary, inspiratory muscle training appears to be effective by improving markers of respiratory muscle function but fails to produce any clinical benefits, in particular on the duration of mechanical ventilation. In the future, the optimal timing to start inspiratory muscle training will need to be determined as well as the target population likely to benefit from this therapy.

Since anabolic steroids increase muscle force in healthy individuals, there is a rationale for their use in patients with diaphragm dysfunction. Although several trials have been conducted in patients with chronic disease, no clear clinical benefits have been identified and they are not indicated in ICU patients. Conversely, the use of inotropes may be of interest to restore diaphragm function. Levosimendan is a cardiac inotrope that exerts positive effects on the contractility of muscle fibers. In healthy subjects, levosimendan reverses diaphragm fatigue and improves neuromechanical efficiency of the diaphragm [45]. However, in a recent trial in which levosimendan was tested to prevent acute organ dysfunction in sepsis, patients who received the drug were more likely to fail weaning from mechanical ventilation $(95 \% \mathrm{CI} 0.60$ to $0.97, p=0.03$ ) [46]. Further studies are therefore needed to elucidate the potential indication of levosimendan in patients with diaphragm dysfunction.

As described above, diaphragm pacing is a novel method that can stimulate the diaphragm. This method could be viewed as an effort to support, maintain and strengthen the diaphragm in patients with weaning failure. A phrenic nerve stimulator has been developed as a temporary, minimally invasive, percutaneously-placed, transvenous pacing system intended for use in conjunction with mechanical ventilation. A randomized controlled trial is currently investigating the effect of diaphragm pacing on weaning outcome (NCT03107949).

As re-intubation is associated with increased mortality, any strategy aimed at reducing the rate of post-extubation respiratory failure and avoiding re-intubation deserves consideration. The benefits of early application of noninvasive ventilation soon after extubation have been assessed in unselected patients and in at-risk patients (i.e., $>65$ years old or patients with underlying cardiac or respiratory disease). Whether diaphragm dysfunction constitutes an additional risk factor for extubation failure has yet to be determined. If this is shown to be the case, further studies may investigate the use of prophylactic non-invasive ventilation in patients with diaphragm dysfunction who are undergoing extubation.

\section{Conclusion}

There is compelling evidence that diaphragm dysfunction is a frequent and serious clinical concern in critically ill patients. In recent years, important progress has been made in the assessment of diaphragm function at the bedside. Whether use of ultrasound is achievable and beneficial beyond the scope of research is an important question that needs to be addressed. Ultrasound may help to better recognize and manage diaphragm dysfunction 
during weaning from mechanical ventilation. Some preventive strategies may be implemented to tailor ventilatory assistance and maintain diaphragm function while patients are ventilated. Finally, some innovative approaches could also enhance the prognosis of patients; in this context, the use of diaphragm pacing is a promising development.

\section{Acknowledgements}

None.

\section{Funding}

M.D. was supported by the French Intensive Care Society, Paris, France (bourse de mobilité 2015); The 2015 Short Term Fellowship program of the European Respiratory Society, Lausanne, Switzerland; The 2015 Bernhard Dräger Award for advanced treatment of acute respiratory failure of the European Society of Intensive Care Medicine, Brussels, Belgium; the Assistance Publique Hôpitaux de Paris, Paris, France and the Fondation pour la Recherche Médicale, Paris, France (FDM 20150734498). Publication costs were funded by ADOREPS (ASSOCIATION POUR LE DEVELOPPEMENT ET L'ORGANISATION DE LA RECHERCHE EN PNEUMOLOGIE ET SUR LE SOMMEIL).

\section{Availability of data and materials}

Not available

\section{Authors' contributions}

$M D$ and $A D$ contributed to drafting the manuscript or critical revision of it for important intellectual content and approved the final version of the manuscript. All authors read and approved the final manuscript.

\section{Ethics approval and consent to participate}

Not applicable

\section{Consent for publication}

Not applicable

\section{Competing interests}

Alexandre Demoule has signed research contracts with Medtronic, Maquet and Philips; he has also received personal fees from Medtronic, Maquet, Resmed, Fisher \& Paykel and MSD. Martin Dres received personal fees from Pulsion Medical System and Lungpacer Inc

\section{Publisher's Note}

Springer Nature remains neutral with regard to jurisdictional claims in published maps and institutional affiliations.

Published online: 20 March 2018

\section{References}

1. Thille AW, Cortés-Puch I, Esteban A. Weaning from the ventilator and extubation in ICU. Curr Opin Crit Care. 2013;19:57-64

2. Béduneau G, Pham T, Schortgen F, et al. Epidemiology of weaning outcome according to a new definition. The WIND study. Am J Respir Crit Care Med. 2017;195:772-83.

3. Epstein SK, Ciubotaru RL, Wong JB. Effect of failed extubation on the outcome of mechanical ventilation. Chest. 1997:112:186-92.

4. Thille AW, Harrois A, Schortgen F, et al. Outcomes of extubation failure in medical intensive care unit patients. Crit Care Med. 2011;39:2612-8.

5. Jung B, Moury PH, Mahul M, et al. Diaphragmatic dysfunction in patients with ICU-acquired weakness and its impact on extubation failure. Intensive Care Med. 2016:42:853-61.

6. Dres M, Dubé BP, Mayaux J, et al. Coexistence and impact of limb muscle and diaphragm weakness at time of liberation from mechanical ventilation in medical intensive care unit patients. Am J Respir Crit Care Med. 2017;195:57-66.

7. Dubé BP, Dres M, Mayaux J, Demiri S, Similowski T, Demoule A. Ultrasound evaluation of diaphragm function in mechanically ventilated patients: comparison to phrenic stimulation and prognostic implications. Thorax. 2017:72:811-8
8. Kim WY, Suh HJ, Hong SB, et al. Diaphragm dysfunction assessed by ultrasonography: influence on weaning from mechanical ventilation. Crit Care Med. 2011;39:2627-30.

9. Berger D, Bloechlinger S, von Haehling S, et al. Dysfunction of respiratory muscles in critically ill patients on the intensive care unit. J Cachexia Sarcopenia Muscle. 2016;7:403-12.

10. Vassilakopoulos T, Petrof BJ. Ventilator-induced diaphragmatic dysfunction. Am J Respir Crit Care Med. 2004;169:336-41.

11. Levine S, Nguyen T, Taylor N, et al. Rapid disuse atrophy of diaphragm fibers in mechanically ventilated humans. N Engl J Med. 2008:358:1327-35.

12. Welvaart WN, Paul MA, Stienen GJM, et al. Selective diaphragm muscle weakness after contractile inactivity during thoracic surgery. Ann Surg. 2011;254:1044-9.

13. American Thoracic Society, European Respiratory Society. ATS/ERS Statement on respiratory muscle testing. Am J Respir Crit Care Med. 2002; 166:518-624.

14. Moxham J, Goldstone J. Assessment of respiratory muscle strength in the intensive care unit. Eur Respir J. 1994:7:2057-61.

15. Watson AC, Hughes PD, Harris LM, et al. Measurement of twitch transdiaphragmatic, esophageal, and endotracheal tube pressure with bilateral anterolateral magnetic phrenic nerve stimulation in patients in the intensive care unit. Crit Care Med. 2001:29:1325-31.

16. Vivier E, Mekontso Dessap A, Dimassi S, et al. Diaphragm ultrasonography to estimate the work of breathing during non-invasive ventilation. Intensive Care Med. 2012;38:796-803.

17. Lerolle N, Guérot E, Dimassi S, et al. Ultrasonographic diagnostic criterion for severe diaphragmatic dysfunction after cardiac surgery. Chest. 2009;135:401-7.

18. Dres M, Schmidt M, Ferre A, et al. Diaphragm electromyographic activity as a predictor of weaning failure. Intensive Care Med. 2012;38:2017-25.

19. Rozé H, Repusseau B, Perrier V, et al. Neuro-ventilatory efficiency during weaning from mechanical ventilation using neurally adjusted ventilatory assist. Br J Anaesth. 2013;111:955-60.

20. Jung B, Nougaret S, Conseil M, et al. Sepsis is associated with a preferential diaphragmatic atrophy: a critically ill patient study using tridimensional computed tomography. Anesthesiology. 2014:120:1182-91.

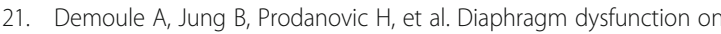
admission to icu: prevalence, risk factors and prognostic impact - a prospective study. Am J Respir Crit Care Med. 2013;188:213-9.

22. Aubier M, Trippenbach T, Roussos C. Respiratory muscle fatigue during cardiogenic shock. J Appl Physiol. 1981;51:499-508.

23. Jaber $\mathrm{S}$, Petrof $\mathrm{BJ}$, Jung $\mathrm{B}$, et al. Rapidly progressive diaphragmatic weakness and injury during mechanical ventilation in humans. Am J Respir Crit Care Med. 2011:183:364-71.

24. Hermans $G$, Agten A, Testelmans $D$, et al. Increased duration of mechanical ventilation is associated with decreased diaphragmatic force: a prospective observational study. Crit Care. 2010;14:R127.

25. Grosu HB, Lee YI, Lee J, et al. Diaphragm muscle thinning in patients who are mechanically ventilated. Chest. 2012:142:1455-60.

26. Goligher EC, Fan E, Herridge MS, et al. Evolution of diaphragm thickness during mechanical ventilation: impact of inspiratory effort. Am J Respir Crit Care Med. 2015;192:1080-8.

27. Zambon M, Beccaria P, Matsuno J, et al. Mechanical ventilation and diaphragmatic atrophy in critically ill patients: an ultrasound study. Crit Care Med. 2016:44:1347-52.

28. Goligher EC, Dres M, Fan E et al (2017) Mechanical ventilation-induced diaphragm atrophy strongly impacts clinical outcomes. Am J Respir Crit Care Med. https://doi.org/10.1164/rccm.201703-0536OC (Sep 20 Epub ahead of print).

29. Garnacho-Montero J, Amaya-Villar R, García-Garmendía JL, et al. Effect of critical illness polyneuropathy on the withdrawal from mechanical ventilation and the length of stay in septic patients. Crit Care Med. 2005;33:349-54.

30. De Jonghe B, Bastuji-Garin S, Durand MC, et al. Respiratory weakness is associated with limb weakness and delayed weaning in critical illness. Crit Care Med. 2007:35:2007-15.

31. Mrozek S, Jung B, Petrof BJ, et al. Rapid onset of specific diaphragm weakness in a healthy murine model of ventilator-induced diaphragmatic dysfunction. Anesthesiology. 2012;117:560-7.

32. Blumhof $\mathrm{S}$, Wheeler $\mathrm{D}$, Thomas $\mathrm{K}$, et al. Change in diaphragmatic thickness during the respiratory cycle predicts extubation success at various levels of pressure support ventilation. Lung. 2016:194:519-25.

33. Ferrari G, De Filippi G, Elia F, Panero F, Volpicelli G, Aprà F. Diaphragm ultrasound as a new index of discontinuation from mechanical ventilation. Crit Ultrasound J. 2014;6:8. 
34. DiNino E, Gartman EJ, Sethi JM, McCool FD. Diaphragm ultrasound as a predictor of successful extubation from mechanical ventilation. Thorax. 2014;69:423-7.

35. Farghaly S, Hasan AA. Diaphragm ultrasound as a new method to predict extubation outcome in mechanically ventilated patients. Aust Crit Care. 2017:30:37-43.

36. Sassoon CSH, Zhu E, Caiozzo VJ. Assist-control mechanical ventilation attenuates ventilator-induced diaphragmatic dysfunction. Am J Respir Crit Care Med. 2004;170:626-32.

37. Gayan-Ramirez G, Testelmans D, Maes K, et al. Intermittent spontaneous breathing protects the rat diaphragm from mechanical ventilation effects. Crit Care Med. 2005;33:2804-9.

38. Reynolds SC, Meyyappan R, Thakkar V, et al. Mitigation of ventilator-induced diaphragm atrophy by transvenous phrenic nerve stimulation. Am J Respir Crit Care Med. 2017;195:339-48.

39. Dres M, Teboul JL, Monnet X. Weaning the cardiac patient from mechanical ventilation. Curr Opin Crit Care. 2014;20:493-8.

40. Dres M, Teboul IL, Anguel N, et al. Extravascular lung water, B-type natriuretic peptide, and blood volume contraction enable diagnosis of weaning-induced pulmonary edema. Crit Care Med. 2014;42:1882-9.

41. Dres M, Roux D, Pham T, et al. Prevalence and impact on weaning of pleural effusion at the time of liberation from mechanical ventilation: a multicenter prospective observational study. Anesthesiology. 2017;126:1107-15.

42. Umbrello M, Mistraletti G, Galimberti A, et al. Drainage of pleural effusion improves diaphragmatic function in mechanically ventilated patients. Crit Care Resusc J. 2017:19:64-70

43. Martin AD, Smith BK, Davenport PD, et al. Inspiratory muscle strength training improves weaning outcome in failure to wean patients: a randomized trial. Crit Care. 2011;15:R84.

44. Bissett BM, Leditschke IA, Neeman T, et al. Inspiratory muscle training to enhance recovery from mechanical ventilation: a randomised trial. Thorax. 2016;71:812-9.

45. Doorduin J, Sinderby CA, Beck J, et al. The calcium sensitizer levosimendan improves human diaphragm function. Am J Respir Crit Care Med. 2012;185:90-5.

46. Gordon AC, Perkins GD, Singer M, et al. Levosimendan for the prevention of acute organ dysfunction in sepsis. N Engl J Med. 2016;375:1638-48.

47. Jiang JR, Tsai $T H$, Jerng JS, et al. Ultrasonographic evaluation of liver/spleen movements and extubation outcome. Chest. 2004;126:179-85.

48. Lu Z, Xu Q, Yuan Y, Zhang G, Guo F, Ge H. Diaphragmatic dysfunction is characterized by increased duration of mechanical ventilation in subjects with prolonged weaning. Respir Care. 2016;61:1316-22.

49. Supinski GS, Callahan LA. Diaphragm weakness in mechanically ventilated critically ill patients. Crit Care. 2013;17:R120.

50. Laghi F, Cattapan SE, Jubran A, et al. Is weaning failure caused by low-frequency fatigue of the diaphragm? Am J Respir Crit Care Med. 2003;167:120-7.

51. Carrie C, Gisbert-Mora C, Bonnardel E, et al. Ultrasonographic diaphragmatic excursion is inaccurate and not better than the MRC score for predicting weaning-failure in mechanically ventilated patients. Anaesth Crit Care Pain Med. 2017;36:9-14. 